\title{
El arte literario y la construcción oral del territorio. Pensamiento crítico afrocolombiano
}

\author{
Literary Art and Oral Construction of the Territory. \\ Afrocolombian Critical Thought
}

\author{
Carlos Alberto Valderrama Rentería* \\ University of Massachusetts, Amherst
}

\begin{abstract}
RESUMEN
En este artículo indago por la tradición oral y la territorialidad en el pensamiento intelectual y político de Rogerio Velásquez Murillo. Empleo su concepto de palenque literario y argumento que dicha expresión es una construcción de sentido que ofrece elementos para considerar un pensamiento crítico afrocolombiano. Propongo entender palenque literario como una forma de lucha típica de las guerras de posición descritas por Antonio Gramsci. El estudio se enmarca dentro de la antropología crítica, la teoría crítica de la raza y la política negra en la diáspora africana, para historizar los significados y usos de las expresiones tradición oral y territorialidad y en los escritos folclóricos y etnográficos publicados en la década de los sesenta por Rogerio Velásquez.
\end{abstract}

Palabras clave: pensamiento crítico afrocolombiano, tradición oral, territorialidad, palenque literario.

\begin{abstract}
In this article, I examine ideas of territoriality and oral tradition in Rogerio Velásquez's intellectual and political thought. I use his concept of palenque literario and argue that this expression reflects an intellectual construction that offers elements for considering Afrocolombian critical thought. I propose to understand this concept as a form of struggle typical of the war of position described by Antonio Gramsci. This study draws from critical anthropology, critical race theory, and Black politics perspectives to historicize the meanings and uses of the concepts of oral tradition and territoriality in Rogerio Velásquez's folkloric and ethnographic writings published in the 1960s.
\end{abstract}

Keywords: Afrocolombian critical thought, oral tradition, territoriality, palenque literario.

Candidato a doctor en Sociología de la University of Massachusetts, Amherst. Entre sus últimas publicaciones están "Intelectualidad crítica afrocolombiana: la negredumbre en el pensamiento intelectual de Rogerio Velásquez Murillo", Revista Nómadas 45 (2016): 216-227, y “Más allá de lo folklorizado", Revista Páginas de Cultura 11 (2016): 15-22. pibeson@gmail.com. 


\section{Introducción}

La profundidad de la historia se actualiza con la Palabra.

Alfredo Vanín

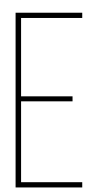

n los últimos años las ciencias sociales colombianas se han interesado por la intelectualidad afrocolombiana. Actualmente se pueden encontrar trabajos académicos que buscan describir y analizar lo que podría llamarse pensamiento crítico afrocolombiano (Arboleda 2016; Caicedo 2013; Friedemann 1984; Leal 2007; Mina 2006; Ortiz 2007; Pisano 2012; Prescott 1996; Valderrama 2013, 2016; Zapata-Cortés 2010). Se trata de un pensamiento cuyo propósito manifiesto es describir, analizar y visibilizar experiencias afrodescendientes en Colombia, país en el que históricamente se ha negado su existencia (Arboleda 2016; Caicedo 2013; Friedemann 1984). El pensamiento crítico está definido por una reflexión profunda sobre la experiencia afrocolombiana propia,

[...] pues se trata primero de superar la exclusión racial estructural, logrando niveles de dignificación de la vida, afianzando la humanidad negada o escamoteada, la capacidad y potencia de ser, la imaginación y la creatividad para resolver la urgencia de sentirse vivos y como personas, superando radicalmente la cosificación de la matriz colonial euroccidental. (Arboleda 2016, 21)

En este trabajo examino el pensamiento intelectual del chocoano Rogerio Velásquez Murillo como una expresión del pensamiento crítico afrocolombiano. Me refiero a la manera como entendió la tradición oral y la territorialidad afrocolombiana en sus escritos etnológicos y folclóricos publicados en la década de los sesenta ${ }^{1}$. Considero que es de vital importancia indagar sobre estos conceptos como indicadores analíticos de un pensamiento crítico afrocolombiano que se distanció de las representaciones andinocéntricas ${ }^{2}$ sobre la región del Pacífico y cuestionó su proyecto de modernidad y orden racial.

Su legado intelectual es amplio y variado: registra trabajos literarios (novelas y poemas), antropológicos, periodísticos, históricos, jurídicos, sociales, entre otros (Antón 2003; Caicedo 2013; Patiño 2010; Rivas 2008), que desbordan los propósitos del presente escrito. Propongo rastrear algunos rasgos de su pensamiento intelectual analizando lo que considero son construcciones intelectuales de importancia para entender aquellas primeras formas de organización social y cultural afrocolombiana de mediados del siglo XX en el Pacífico colombiano.

2 Expongo la idea de representaciones andinocéntricas a partir de la noción andinocentrismo formulada por Arocha y Moreno (2007). Con este término sugiero aquellas representaciones racializadas que se producen en los centros andinos de poder blanco-mestizo sobre las zonas 
Sitúo el pensamiento intelectual dentro del entramado campo de prácticas sociales y culturales mediante las cuales los sujetos negocian relaciones de poder (Gregory 1998) y construyen espacios discursivos subalternos (Fraser 1990), que revelan sus proyectos políticos comunes o divergentes. Por tal motivo, la constitución de una intelectualidad afrocolombiana crítica se debe entender como parte de los repertorios, mecanismos o formas de lucha social y cultural afrocolombianos en su larga duración. Aquí, la letra y la escritura a "mano alzada" (Caicedo 2013) se constituyen como "instrumento de combate del negro" (Zapata 1977, 119) en la "batalla cultural e ideológica" (Wallerstein 1999) que disputa el campo de contienda sobre las representaciones racializadas que se han hecho de las comunidades negras desde la mitad del siglo XX en la sociedad colombiana. En tal sentido, el pensamiento intelectual y crítico también es una forma de acción política que revela proyectos, deseos y utopías.

Este artículo se enmarca dentro de la antropología crítica (Trouillot 2003), la teoría crítica de la raza (race critical theory) (Essed y Goldberg 2002) y la política negra en la diáspora africana (Caicedo 2013; Lao-Montes 2010). Estas perspectivas registran una pluralidad de definiciones sobre lo que podría entenderse como un pensamiento e intelectualidad crítica afrocolombiana: el intelectual orgánico (Gramsci 1971), el intelectual público (Dawson 2001; Hanchard 2006), el intelectual nativo (Fanon [1963] 2004), el intelectual vernáculo (Farred 2003), el intelectual de la diáspora afrocolombiana (Caicedo 2013) y el intelectual radical (Arboleda 2016; Bogues 2003).

El intelectual crítico afrocolombiano que propongo tiene la mirada crítica del intelectual orgánico de Gramsci (1971), al entender que su función es en favor de los subalternos 3 . Por lo tanto, al cuestionar el sistema racial colombiano, el intelectual crítico reconoce los acontecimientos históricos y estructurales (racismo, colonialismo, capitalismo) sobre los cuales se configuran la subordinación y sujeción de las comunidades negras. De ahí su pensamiento radical (Bogues 2003), afrodiaspórico (Caicedo 2013) y decolonial (Arboleda 2016), ya

del "trópico salvajismo" donde sus habitantes son estereotipados como salvajes, bárbaros, perezosos y lisonjeros, a partir del color de la piel (Arboleda 2016; Arocha y Moreno 2007; Pisano 2013; Wade 1993).

3 Para Gramsci, el intelectual orgánico responde a procesos organizativos y políticos de lucha de clases. Estos intelectuales cumplen las funciones de informar y organizar a sus colectivos. En el contexto de la lucha política, el intelectual orgánico emerge, por un lado, al servicio de las clases dominantes y legitimando el orden y modelo económico. Por otro lado, el intelectual orgánico subalterno emerge de los procesos subalternos que resisten a la dominación (1971). A pesar de los límites del modelo del intelectual de Gramsci (dada su reducida mirada a la lucha de clases), su propuesta teórica nos ayuda a comprender la función política del intelectual con su grupo social. Así, el intelectual crítico afrocolombiano se debe a sus comunidades negras, las cuales debe fortalecer en los procesos de luchas sociales. 
que además de develar las fuerzas de poder que se conjugan para oprimir a las comunidades negras, propone soluciones de manera radical. En este sentido, el pensamiento crítico se vincula con el pensamiento del intelectual nativo (Fanon [1963] 2004), porque su propósito es probar que la cultura negra existe (212) y que es proyectada desde la defensa propia de quien se reconoce como parte de ella (212) ${ }^{4}$. Es así como, al rastrear su entendimiento de la tradición oral y las formas de territorialidad en los procesos de organización social y cultural de las comunidades negras en la región del Pacífico, la intelectualidad de Rogerio Velásquez debe reflejar los ideales o visiones de un pensamiento crítico que privilegia a las comunidades negras como protagonistas principales de sus narrativas y acontecimientos históricos.

Tradición oral y territorio son conceptos centrales en el análisis del pensamiento crítico de Rogerio Velásquez. La tradición oral se entiende como aquellos repertorios orales, tales como mitos, leyendas, adivinanzas, cuentos, relatos, historias y cantos, cuyo contenido ha logrado preservar rasgos generales y discontinuos de una memoria histórica, social y cultural de acontecimientos históricos que han contribuido a los procesos de formación comunitarios e identitarios de las comunidades negras (Almario 2001; Losonczy 1999; Vanín 1996). Por su parte, el territorio se toma desde su dimensión simbólica, a partir de su construcción social y cultural, es decir, de los significados y sentidos atribuidos a él (Almario 2001; Pedrosa, Vanín y Motta 1994). En este orden de ideas, el territorio es una construcción de sentido narrado, contado y cantado por protagonistas afrocolombianos.

Para el análisis de tradición oral y territorio hice una lectura rigurosa de los trabajos folclóricos y etnográficos publicados a mediados del siglo XX en Colombia que tienen como tema central la tradición oral ${ }^{5}$. Utilicé herramientas analíticas de la antropología y la teoría crítica de la raza y me basé en la propuesta metodológica de Trouillot (2003), quien sostiene que "las conceptualizaciones

$4 \quad$ En la versión inglesa de Los condenados de la tierra (Groves Press, 1963) aparece la expresión intelectual nativo (native intellectual). En una nueva versión de la misma editorial, publicada en el 2004, intelectual nativo es reemplazado por intelectual colonizado (colonized intellectual). Para la presente reflexión, uso la primera edición. En el capítulo “On National Culture” (206-248), Fanon establece tres etapas en las que el intelectual nativo se forma como intelectual anticolonial. La primera es de asimilación, y en esta el intelectual nativo se sumerge en la cultura del colonizador y la reivindica. La segunda es de dudas, cuando el intelectual nativo empieza a cuestionar los principios culturales del colonizador poniendo en juego su propia memoria y experiencia con la gente subordinada. La tercera etapa es la de lucha social, y allí el intelectual nativo asume un compromiso participativo y militante con la gente subordinada con la que se siente comprometido (Fanon [1963] 2004, 222-23; traducción propia). La idea de intelectual nativo que tomo para este artículo se refiere al intelectual en la etapa de lucha social.

$5 \quad$ Esto significa que, para el presente estudio, aquellos trabajos que no tienen como tema central las tradiciones orales afrocolombianas fueron excluidos. 
siempre son (construcciones) históricamente situadas" (98), y que "si observamos el contexto como una condición posible de conceptualización, una historia diferente surgirá [...]" (99). De esta forma, historicé usos y construcciones de sentido sobre palabras, términos o metonimias que asociamos con la tradición oral y el territorio. Por ejemplo, para el caso de la primera, tuve en cuenta palabras como leyendas, mitos, folclor chocoano, adivinanzas, etc. Para el caso del territorio, establecí los lugares y relaciones sociales y culturales en los cuales tenía lugar la tradición oral.

Este conjunto de elementos fue objeto de análisis denotativos y connotativos (Hall 1997; Lawrence 2007). En el primer caso interpreté sus sentidos planos. Es decir, lo que representan semánticamente en sus relaciones con el conjunto de palabras, términos y frases que los acompañan en el texto. Para el análisis connotativo consideré el contexto social, cultural y político de la época, así como los intereses, preocupaciones y motivaciones del autor en relación con otros intelectuales negros de lo que se ha denominado el campo político intelectual afrocolombiano (Arboleda 2016), asociado con Delia y Manuel Zapata Olivella, Aquiles Escalante y Teófilo Potes, entre otros. Así mismo, he leído la obra de Rogerio Velásquez teniendo en cuenta el contexto ideológico del mestizaje y sus implicaciones prácticas de invisibilización de lo afrocolombiano en el proceso de construcción de la nación, las representaciones de la región del Pacífico como negra (Wade 1993) y la emergencia de los estudios antropológicos que privilegiaron a las comunidades indígenas como sus "objetos" de estudio.

La estructura del documento es la siguiente: en la primera sección presento una breve descripción de la trayectoria intelectual de Rogerio Velásquez basada en fuentes secundarias. En la segunda me aproximo a su pensamiento crítico mediante el examen de las ideas de tradición oral (arte literario) y la construcción oral del territorio a partir de fuentes primarias y a la luz de trabajos especializados sobre tradición oral (Almario 2001; González 1997; Hanétha 2016; Losonczy 1999; Oslender 2003; Pedrosa, Vanín y Motta 1994; Solarte 2008; Vanín 1996; Vété-Congolo 2016). Sugiero usar la expresión del autor palenque literario como concepto que describe los espacios locales afrocolombianos donde la tradición oral ha tenido lugar como práctica social y cultural. Propongo que el palenque literario contiene características de lo que llamo espacios públicos afrocolombianos y nos sugiere procesos de continuidad histórica en las luchas sociales de un régimen dictatorial (las colonias, por ejemplo) a otro "democrático"6.

6 Según la teoría crítica sobre raza (Omi y Winant 1994), las formaciones raciales ocurren en procesos sociohistóricos en los cuales se crean, heredan, transforman y destruyen categorías raciales; este es un proceso de larga duración que involucra diferentes regímenes de poder. 
Finalmente, considero algunas implicaciones académicas y políticas frente a las dinámicas sociales y culturales que busco rescatar con la expresión palenque literario.

\section{Pensamiento crítico afrocolombiano en las márgenes de la intelectualidad colombiana}

Rogerio Velásquez nació el 9 de agosto de 1908 en Sipí, un poblado sobre el río del mismo nombre, tributario del río San Juan, en el departamento del Chocó. Pasó su infancia en Istmina y en Condoto, donde realizó sus estudios primarios. Cursó la secundaria en el colegio Tomás Carrasquilla de Quibdó y en la Normal de Varones de Bogotá. Posteriormente, se trasladó a la Central de Institutores de Tunja donde, en 1938, se graduó como institutor con el trabajo de grado "La higiene en Colombia” (Antón 2003). De acuerdo con Caicedo (2013), los programas humanistas ofrecidos por la Normal Superior influyeron en el pensamiento e interés del chocoano por el estudio de las ciencias sociales, en particular, la historia y el derecho.

En 1948, Rogerio Velásquez obtuvo el título de etnólogo del Instituto Etnológico del Cauca, dirigido por Gregorio Hernández de Alba. Según Caicedo (2013), este fue fundamental en la formación de Velásquez. La participación de Hernández de Alba en la Primera Conferencia Internacional de Arqueólogos del Caribe, llevada a cabo en 1946, en cuyas conclusiones se invitaba a los gobiernos y universidades de América a intensificar el estudio de las influencias de las culturas negras, pudo haber facilitado el reconocimiento del estatus científico de los estudios afroamericanistas en Colombia y el posterior giro hacia la negritud tomado por Velásquez (Caicedo 2013). Además de la docencia, Rogerio Velásquez ocupó cargos administrativos y políticos en el Chocó entre 1948 y 1953. Después fue nombrado investigador auxiliar del Instituto Etnológico Nacional y jefe de la Sección Folclórica de la entidad. Por doce años estuvo vinculado al Instituto Colombiano de

Utilizando el concepto de hegemonía de Gramsci, Omi y Winant diferencian dos: al primero lo llaman dictadura racial (racial dictatorship), en el que hay una negación jurídica del otro racializado y las sociedades se organizan a partir de la diferencia en el color de piel, lo que lleva a una exclusión total del sujeto racializado de los espacios de participación públicopolíticos. El sistema colonial y el Jim Crow son ejemplos de una dictadura racial. El segundo tipo de régimen es el democrático; allí hay una apertura en los espacios público-políticos y los subalternos racializados pueden participar en las instituciones políticas. Si en el régimen dictatorial predomina el poder basado en la coerción y la violencia física, en los regímenes democráticos (por ejemplo, la formación de repúblicas democráticas) el poder se expresa a través del consentimiento y el sentido común. 
Antropología como jefe de la Sección Folclórica. Finalmente, murió en Quibdó el 7 de enero de 1965, cuando era rector del colegio Tomás Carrasquilla.

Rogerio Velásquez fue uno de los pioneros en los estudios afroamericanistas y uno de los primeros etnólogos/antropólogos colombianos que estudiaron las culturas y sociedades afrocolombianas en el país (Friedemann 1984). Su producción bibliográfica es amplia y variada. Escribió poesía y publicó novelas, crónicas periodísticas, investigaciones folclóricas e históricas (Antón 2003; Rivas 2008) pero, a pesar de su trayectoria y versatilidad intelectual, no ha tenido el reconocimiento académico que merece (Friedemann 1984). Desde sus inicios tuvo que producir conocimiento en las márgenes de la intelectualidad colombiana. Su formación disciplinar como etnólogo se dio en el contexto del indigenismo nacionalista preocupado por entender los orígenes de la cultura nacional colombiana en el pasado indígena, perspectiva que negaba la existencia de una cultura afrocolombiana, lo que motivó la denuncia de Velásquez (1962):

[...] en Colombia, donde el negro está sin estudiar, por el escaso interés que ha despertado en su historia y en sus patrones de respuesta establecidos frente a sus necesidades, vale la pena revelar parte de los nombres que se dieron a los desventurados africanos que arribaron al Nuevo Reino de Granada por la avaricia de los europeos. (113)

La cita anterior expresa un posicionamiento intelectual crítico y propositivo del autor frente al "escaso interés que ha[bía]n despertado" los estudios de las comunidades negras en las nacientes ciencias sociales colombianas; preocupación compartida con otros intelectuales afrocolombianos del momento, como Aquiles Escalante, Manuel Zapata Olivella, Delia Zapata Olivella y Teófilo Potes ${ }^{7}$.

Los trabajos de Velásquez revelan un compromiso intelectual con la visibilización y revaloración ${ }^{8}$ de las expresiones culturales de las comunidades afrocolombianas del país. En sus trabajos etnográficos y folclóricos, así como en su novela Las memorias del odio, Velásquez no solo da protagonismo e importancia a los sujetos afrocolombianos y sus culturas, sino que también define su propia identidad como parte de ellas. En este doble proceso de afirmación cultural e identitaria, usó términos raciales específicos para describirlas. Según Claudia

7 Existe un campo significativo del pensamiento crítico afrocolombiano por estudiar: las influencias entre los intelectuales afrocolombianos y afroamericanistas como Thomas J. Price, José Rafael Arboleda y Aquiles Escalante que emergieron a mitades del siglo XX. Si bien los trabajos consultados (Arboleda 2016; Caicedo 2013; Friedemann 1983; Leal 2007; Mina 2006; Ortiz 2007; Pisano 2013; Prescott 1997; Valderrama 2013, 2016; Zapata-Cortés 2010) contribuyen en este sentido, aún queda mucho por profundizar.

8 Para entender la importancia de la idea de la revaloración de la tradición cultural en los procesos decoloniales de los pueblos oprimidos, véase Arboleda (2016, 110-114). 
Leal (2007), “Velásquez no solo habla de negros [...] y del 'negro' [...] también se refiere a la negredumbre [...] y a la raza negra [...]. En otros casos habla de sus corraciales [...], de la raza [...] y de mi raza [...]” (79), lo que desde mi perspectiva evidencia una conciencia y un compromiso racial manifiesto con las comunidades negras que, como él, han sido formadas “entre la vida de la selva, los ríos y la palabra que cuenta y canta en esta región negra de Colombia” (Caicedo 2013, 446).

Como etnógrafo, la mayoría de sus investigaciones y producciones bibliográficas no fueron publicadas en revistas y boletines de etnología, arqueología o antropología, sino en revistas folclóricas (Friedemann 1984), lo que probablemente influiría en el escaso interés académico por su pensamiento crítico sobre cuestiones antropológicas. De ahí que sus planteamientos acerca de la tradición oral y la territorialidad no hayan tenido ninguna consideración intelectual y académica hasta el momento. En particular, su idea de palenque literario revela un pensamiento crítico y propositivo de las formas autónomas de organización social y cultural de las comunidades negras en el Pacífico ${ }^{9} \mathrm{y}$ frente a procesos de exclusión racial que negaron (y niegan) su existencia.

\section{El arte literario de la tradición oral afrocolombiana}

La tradición oral tiene hoy un estatus académico y es reconocida como un texto o un documento reflexivo en el cual los investigadores pueden acceder a la memoria histórica y cultural de un pueblo (Escobar 2008; Losonczy 1999; Oslender 2003). Se denomina como historia oral, literatura oral, oralitura, testimonio oral, arte popular, la palabra florida, y disciplinas como la antropología, la historia, la lingüística, la sociología, los estudios culturales y subalternos hacen uso de ella en sus desarrollos investigativos.

En los trabajos folclóricos de Rogerio Velásquez encontramos registros similares sobre su concepción de tradición oral. En los años cincuenta, cuando en Colombia los intelectuales y políticos blancos-mestizos negaban la existencia de una cultura negra, considerándola bárbara, salvaje, lisonjera y de perezosos (Friedemann 1984; Villegas 2008; Wade 1993), y cuyos proyectos políticos

9 Me refiero a que palenque literario es una modalidad más de las formas autónomas de organización social y cultural de las comunidades negras, tales como las familias de tronco, las construcciones territoriales y los procesos organizativos y comunitarios de tipo rural y urbano (Arboleda 2017; Escobar 2008; Losonczy 1999; Oslender 1999, 2003, 2011; Villa 2000). 
buscaron modernizar a la nación colombiana mediante "la disciplina" o "el poblamiento” (Castro-Gómez 2007; Villegas 2008), Velásquez dio “estatus, entidad y rango literario” a la tradición oral afrocolombiana (Rivas 2008, 59). Para él era un error reducir la literatura a la escritura, dado que "la palabra no se expresa exclusivamente en forma escrita” (Solarte 2008, 244):

Así llegamos al arte literario, a la canoa considerada como objeto de la belleza escrita. Origen del canto ha sido ella en el Alto como en el Bajo Chocó. Mineros y leñadores, pecheros y plebeyos del Pacífico y de más de trescientos ríos que se enredan desde Ardita hasta el riachuelo Mataje, han creado el cancionero que la exalta [...]. (Velásquez 1959b, 112-113)

Esta referencia del arte literario se encuentra en el artículo "La canoa chocoana en el folklore” (Velásquez 1959b), donde hace una maravillosa descripción histórica, social, económica y cultural de la canoa chocoana. Allí, identifica seis funciones específicas de la canoa en la región que permitirán entender "mejor el saber popular de una comarca que razona a su manera, crea sin discutir ni examinar, acepta y repite sus invenciones espontáneas sin caer en el cientificismo de dudar y comprobar" (1960a, 109). Me detendré en la función estética en la que Velásquez combinó las palabras estética, arte literario y tradición oral (1959b, 109-113). Primero, el fragmento anterior revela que para el autor el arte literario se refiere a coplas, cantos, mitos y leyendas; a decires y dichos, y a la capacidad creativa y productiva de los hombres y las mujeres afrodescendientes del Pacífico colombiano de contar y cantar sus experiencias y su relación con el río. Segundo, deja de manifiesto la revaloración (Arboleda 2010, 2016) de Velásquez de la tradición oral afrocolombiana, a la que atribuye virtud, ingenio, creatividad, dominio artístico y estético, y a la cual denomina arte literario - atributos culturales y morales de las comunidades negras del país impensados en ese momento histórico-.

Tercero, llama la atención que Velásquez emplee la expresión arte literario y no folclore literario, arte folclórico, arte popular o literatura popular, que era como comúnmente se refería a las expresiones culturales de los sectores subalternos y las clases populares. Hay que recordar que en la década de los sesenta la idea de arte estaba directa y exclusivamente asociada a las "bellas artes", al "arte clásico" o la "alta cultura". Lo anterior no significa que no usara también los términos folclore o cultura popular. A mi modo de ver, el uso de la expresión arte literario significa que, para el autor, aun siendo expresiones folclóricas y populares, la tradición oral no dejó de ser siempre un arte de creación literaria.

Cuarto, el fragmento refleja los actos de cada momento de la vida, contados y narrados por individuos dotados y equipados para el oficio de narrar, 
conservar o recitar la experiencia de las comunidades negras en la región pacífica. Para Velásquez (1960c), la tradición oral es un arte creativo que les ha permitido a los afrochocoanos desarrollar competencias intelectuales en la marginalidad: "para la población negra del Chocó, una adivinanza es gimnasia mental, competencia intelectual, un pasatiempo. Aldeas sin libros, con habitantes sin distracciones de ninguna índole, sus componentes tienen que aglomerarse en torno de cosas simples y rurales” (103-104).

A partir de lo anterior, se podría suponer que para Velásquez la tradición oral de las comunidades afrocolombianas ha sido un mecanismo clave a través del cual la memoria colectiva se ha mantenido viva (Motta 1997), fluida (Pedrosa, Vanín y Motta 1994; Vanín 1996) y en plural (Losonczy 1999). También comparte con Manuel Zapata Olivella la idea de que "la tradición oral en nuestros países preserva en forma dinámica la filosofía, el comportamiento y el ideal de los oprimidos [...]" (Zapata 1983, 123).

No podía ser de otra manera. Negada la escuela a que tiene derecho por la dispersión de los poblados y la escasez mental de los que lo gobiernan con altanería y desprecio, tiene que filosofar así a su manera, sin haber otro libro que el grande de la naturaleza y sin haber ahondado en otra sistemática enseñanza que sus propios dolores. (Velásquez 1960a, 35)

Es claro, entonces, que para Velásquez la tradición oral no solo refleja la filosofía, el comportamiento y los ideales de los oprimidos, sino también su condición marginal y subalterna, como lo denunció Sofonías Yacub en su famoso Litoral recóndito (1934). Así entendida, la tradición oral no es solo un estilo de vida (Motta 1997), es también el resultado histórico de relaciones de poder y dominación racial, tal como lo plantearon intelectuales como Delia y Manuel Zapata Olivella y Teófilo Potes (Valderrama 2014).

Allí, en medio de sus ríos, uncido a la trata y a las actas, quemado por un sello antisocial inhumano, y por el hierro de la cifra, trasoyendo su África en los impulsos instintivos que le permitió conocerse. Al identificarse como hombre, al lograr su primer empeño de ser libre, cantó su vinculación con la vida y con el universo. (Velásquez 1948, 21)

Mientras las ciencias sociales como la sociología y la historia reducían sus explicaciones a las desigualdades de clase (Leal 2010), Velásquez entendía que el problema del afrocolombiano, su marginalidad y las condiciones materiales de su exclusión debían ser explicados en la articulación de clase, raza y herencia colonial:

Para hablar del folclor chocoano hay que partir del hombre. El incremento de la esclavitud, la dureza de los señores de Popayán y de An- 
tioquia, el ansia de oro en aquellas dilatadas regiones, la equivocada y desmedida caridad del Padre de las Casas, clavó, bajo un cielo tempestuoso y en selvas desmayantes, al hombre de color que, lavando oro para sus amos, se ha ido mezclando con las otras razas y con los azares de la patria. (Velásquez 1948, 21)

Al igual que la literatura escrita, para Rogerio Velásquez, la tradición oral del hombre de color es fuente de ricas narrativas históricas que reflejan la viveza y capacidad del pensamiento humano, las diferentes visiones del mundo, los conocimientos locales, las formas de construir un pasado, un presente y un futuro (Pedrosa, Vanín y Motta 1994; Zapata 1983), aquello a lo que en la actualidad se le ha dado el nombre de ontologías políticas (Escobar 2008):

[...] hay que oír la riqueza de voces y de giros de estos campesinos que no han ido a la escuela, a través de un acertijo. Con ligeros arcaísmos, pausada y lentamente, el chocoano sostiene la audiencia inquiriendo y respondiendo con un idioma fácil que enaltece el pasado y conforta para el porvenir [...]. (Velásquez 1960c, 104)

Es claro para mí que el pensamiento intelectual de Velásquez le da un protagonismo al afrocolombiano y reconoce las capacidades de este para interpretar en detalle la "ecosofía popular” chocoana (Oslender 2003, 210). El afrocolombiano no es un salvaje, bárbaro e incivilizado - como era representado de manera predominante en la década de los cincuenta-, por el contrario, es un "artista" de la literatura oral en condiciones de marginalidad racial.

Finalmente, hay una concepción política de la tradición oral en el pensamiento intelectual de Velásquez. Aquí la idea de política no tiene nada que ver con la visión institucional y corporativista de esta. Tampoco hace alusión a la idea de política que los nuevos movimientos sociales han desarrollado con sus prácticas participativas y democráticas (Melucci 1999). Su concepción política de la tradición oral puede ser entendida como un sitio de resistencia (Oslender 2011, 151). Según Oslender (2011), la tradición oral es un vehículo de cohesión social y cultural que permite la recuperación de una memoria colectiva afrocolombiana. Como tal, es el lugar donde se han desarrollado formas de contralenguajes que alcanzan límites insospechados. Así, aun cuando la colonización europea por la vía del lenguaje fue avasallante, esta "generó en el Pacífico una especie de contralenguaje; el lenguaje fue impuesto, pero como reacción cultural, se creó otro, porque los deseos de libertad o de pertenencia están ligados al lenguaje que compartimos” (Vanín 1996, 47).

Si tenemos en cuenta lo anterior, el contralenguaje es la manera como el afrocolombiano del litoral pacífico ha hecho suyas las estructuras literarias 
españolas de la décima y la copla para convertirlas en parte insustituible de su expresión y de su vida cotidiana, les dio su "profundación” (Vanín 1996, 59). Esto es lo que, en palabras de Lao-Montes (2010), podría llamarse afromodernidades del arte literario. A este respecto, Oslender (2003) sostiene que, "donde hay visiones y versiones de memoria en competencia y se impone la versión dominante se produce una contramemoria en la visión subordinada que lucha por su sobrevivencia y su articulación en formas múltiples y frecuentemente ocultas” (222). Por tal motivo, puedo argumentar que para Velásquez el arte literario afrocolombiano, su contramemoria colectiva, contiene un contralenguaje que lucha contra el olvido (bell hooks en Oslender 2003, 221) del conflicto racial que la ideología del mestizaje y la armonía racial han pretendido negar e invisibilizar:

Hállanse en estos versos complejos raciales, diferencias de castas, choques de culturas. El africano que empezaba a escalar la cuesta que conduce a la dignidad humana, y la civilización europea del blanco que encaraba los problemas de acuerdo con ella y con las circunstancias, produjo esta lucha de criterios que, plasmados en decires rimados, se quedó en la memoria de mineros y terratenientes del extinguido Cauca grande, emociones que saltan de tarde en tarde como derrotero de conducta o como garfio que escarba doloroso un poco más adentro de la carne. (Velásquez 1960b, 13)

Como lo expresé al inicio, es claro que la visión politizada de la tradición oral en el pensamiento intelectual de Velásquez es una concepción que ve el arte literario como un "instrumento de combate del negro" (Zapata 1977, 119):

Porque la característica de estas coplas radica en que todavía las emplean los blancos contra los negros y estos contra aquellos. Van y vienen como saetas de combate que se clavan en el corazón del contrario haciéndolo sangrar. Son armas [...]. (Velásquez 1960b, 13)

Al igual que Manuel Zapata Olivella, reconoce que "[...] la palabra viva, ágrafa, es el grito del oprimido. La tradición oral, pues, para nosotros posee una connotación liberadora, la dramática voz del humillado, cuya historia ha sido tergiversada y proscrita” (Zapata 1983, 122). 


\section{Palenque literario. La construcción oral del territorio}

Comparto el argumento que sugiere entender la tradición oral como parte o resultado de formas propias de organización social y cultural. Agudelo (2005) propone el concepto de organizaciones simbólicas para referirse a las relaciones sociales, los significados y símbolos que generan las comunidades negras frente a su realidad y que devienen luego en señales de identificación. Vété-Congolo (2016) sugiere los conceptos de árboles de las palabras (trees of words) y casas de las palabras (houses of words) para referirse a los espacios en los que la palabra puede ser ofrecida "[...] y la comunicación puede circular de acuerdo con ideas de respeto, orden y equidad” (8). A partir de los trabajos de Rogerio Velásquez propongo la idea de palenque literario como una expresión descriptiva que nos permite acercarnos a las relaciones sociales y culturales en las que el arte literario circula como medio de comunicación y pensamiento. En este sentido, debe entenderse como un concepto que puede revelar la manera como el autor chocoano se aproximó a las formaciones sociales y culturales afrocolombianas y que desde ahí planteó alternativas para entenderlas en sus propias dinámicas relacionales ${ }^{10}$. Veamos.

En sus trabajos, Rogerio Velásquez parece referirse a espacios literarios con características similares a los espacios públicos subalternos o contrapúblicos ${ }^{11}$. Su carácter social se da en la medida en que hombres y mujeres afrocolombianos se

10 Hay que señalar que palenque literario no fue pensado como un concepto antropológico, sociológico o analítico. Más bien, es una metonimia que se refiere a situaciones o aspectos sociales o culturales que Velásquez observó en sus trabajos etnográficos y folclóricos en el Chocó. Al ser una metonimia, revela mucho más que un pensamiento que sistematiza y recopila producciones orales populares, como lo sugiere Motta $(1997,33)$. Por eso, mi intención aquí es realizar una aproximación comprehensiva de una posible conceptualización antropológica de este que nos permita observar fenómenos culturales similares en la actualidad.

11 En mi tesis doctoral trabajo la idea de públicos subalternos o contrapúblicos afrocolombianos a partir de la propuesta de espacios públicos subalternos (Dawson 2001; Fraser 1990). Este concepto busca suplir las limitaciones teóricas de los espacios públicos burgueses propuestos por Jürgen Habermas (1991). Según Fraser y Dawson, Habermas no reconoció otros espacios públicos constituidos por subalternos, tales como los espacios públicos feministas, afroamericanos y de la comunidad LGBTI. Por otro lado, tendríamos que ampliar el concepto de espacios públicos subalternos propuesto por Fraser para incluir la idea de palenque literario. Es decir, para reconocer aquellos espacios públicos donde los medios de circulación de ideas, pensamientos y discursos no están relacionados con formas modernas del pensamiento letrado y escrito. Con palenque literario propongo una "lectura emergente" de los espacios públicos subalternos (en el sentido propuesto por Flórez [2010] para el caso de las perspectivas sobre movimientos sociales en Latinoamérica) para entender aquellos espacios públicos subalternos afrocolombianos por donde ha circulado el pensamiento crítico y libertario a través de la tradición oral. 
encuentran y relacionan para contar y cantar lo recorrido, lo gozado y lo sufrido, a la vez que se lo inventan (Vanín 2012, 1). La habilidad para hablar y el acto mismo del habla se expresan de varias maneras que se refieren a aspectos de la vida material y espiritual. De ahí su naturaleza artística, literaria y cultural. El carácter de lo público en estos espacios del arte literario se refiere a la audiencia que escucha y que en algunos momentos interactúa con los contadores y las cantadoras. Esta varía dependiendo de la ocasión; existen diferencias entre velorios, celebraciones o espacios de esparcimiento espontáneos, que son espacios de socialización y construcción colectiva:

Los cuentos se echan en cualquier parte del caserío. En habitaciones lujosas y bohíos, en ranchos mineros y labranzas, en las orillas de las sementeras, sobre canoas perezosas o en playas afiebradas. Basta que la situación sea propicia. Mientras se cuecen los alimentos o después de la merienda, en los actos sociales o en la hora de aconsejar, surge el ejemplo, la rústica creación breve que facilita el recreo y la enseñanza moral para el gobierno del espíritu. (Velásquez 1959a, 6)

Pedrosa, Vanín y Motta (1994) sugieren que tanto la cultura como la historia del Pacífico colombiano se han desarrollado en tres escenarios: los ríos, el mar y la selva. Así, los espacios y relaciones sociales donde tiene lugar el arte literario no hacen alusión a espacios acuáticos (Oslender 1999) o al sentido de lugar acuático (Oslender 2003, 2011) exclusivamente. Estos lugares y espacios del arte literario connotan una construcción social en la que lo físico, lo geográfico, lo social y lo cultural se articulan para dar vida a espacios públicos afrocolombianos en la región. En este sentido, Rogerio Velásquez nos sugiere una construcción de sentido mítico-poética del territorio que pertenece al mundo de lo relacional; es decir, una construcción del territorio definido por las interacciones simbólicas de lo físico, lo humano, lo ambiental y lo espiritual (Escobar 2015). Es una creación intelectual que también nos indica la construcción artístico-literaria del sentido de lugar (Escobar 2008; Oslender 2003, 2011) sin límites (Villa 2000), en la que las familias afrocolombianas desarrollaron un modelo de campesinado libre, autárquico y que se resistió a formar núcleos de naturaleza urbana (Villa 2000).

Al llamar a estos espacios del arte literario palenques literarios, propongo verlos como espacios públicos afrocolombianos de las comunidades de habla y pensamiento (Atencio y Castellanos, en Pedrosa, Vanín y Motta 1994, 84) que han servido para la construcción cultural del territorio (Vanín 2012, 1). En este sentido, el palenque literario es una metonimia cuya composición semántica nos extiende una invitación a pensar en el valor connotativo del pensamiento libertario de los palenques cimarrones. Así, la idea de palenque insinúa una continuidad 
histórica con las formas de lucha y conflicto social que se desarrollan en el paso de un régimen dictatorial a otro democrático. En el primer caso, las llamadas guerras de maniobra (Gramsci 2006) se refieren a formas del cimarronaje violento y no violento (Flórez 2010, 95) que buscaron la libertad física y espiritual, a través de estrategias armadas, la conformación de palenques y el uso de prácticas mágico-religiosas de origen africano para paralizar a los esclavizadores y sus negocios de explotación, en lo que Enrique Dussel llama la primera modernidad (Flórez 2010, 92-96).

Las segundas formas de lucha y conflicto social se refieren a las guerras de posición (Gramsci 2006), que ocurren en los regímenes democráticos en los que los subalternos tienen la posibilidad de ocupar posiciones dentro de la sociedad y de las instituciones públicas. En este caso, las luchas y los conflictos sociales se desarrollan por la hegemonía de las ideas y del pensamiento político ${ }^{12}$. La noción de palenque literario que retomo de Rogerio Velásquez (1960b) correspondería a las guerras de posición en las sociedades democráticas. Así lo describe el autor:

Las coplas [...] [p]ronunciadas con el ánimo deliberado de imponer un prestigio en el Palenque Literario, o para arrebatar un cariño que seguía con los ojos y la inteligencia el armonioso desafío, [...] la aventura del verso y el apasionando candor de las estrofas iban punzando, sembrando inquietudes en el auditorio enardecido [...] (83; énfasis añadido)

Si, como lo señala Gramsci (1971, 5-10), cada grupo social crea su propio tipo de intelectual orgánico, palenque literario se refiere, entonces, a aquellos espacios públicos afrocolombianos donde la tradición oral ha cultivado un pensamiento libertario afrocolombiano. Al respecto, Rogerio Velásquez (1948) observó:

Negro, filósofo y crítico, sigue cantando, mostrando al mundo por medio de tu cañudo salvaje, la realidad tremenda de un pueblo que si desaparece del mapa de la patria total no será, [...] por culpa de los que mueren amándolo [y] sirviéndolo, pensando en lo que vale ser colombiano. Los nativos han permanecido fieles a una tradición de libertad que fuerzas oscuras flagelan y, sin temor al olvido, a los vejámenes y al hambre, con la cabeza erguida, sin ceder al dolor, siguen llevando en alto el pabellón de la República [...] (29; énfasis añadido)

Permítanme reproducir una cantata registrada por Velásquez (1960b) que refleja el pensamiento libertario que la tradición oral ha recreado en el devenir

12 Las guerras de posición no niegan la emergencia de guerras de maniobra en una sociedad democrática. Hago la distinción por motivos heurísticos que permitan señalar tendencias hegemónicas que se presentan de un régimen dictatorial a otro democrático, véase Gramsci (2006). 
histórico de la conformación de formas autónomas de organización social y cultural afrocolombianas en el Pacífico: "Mi dicha solo consiste... en tener mis platanales... En ser como el viento, libre... sin mandarín que me mande” (35).

El pensamiento libertario también se puede hallar en las historias y cuentos sobre el origen de las naciones blanca y negra. En un relato quibdoseño llamado el "Origen de la raza blanca", el color de la piel es fundamental en la definición de la diferencia racial, entre la nación blanca y la nación negra, y entre lo bueno y lo malo. Contrario a la versión hegemónica, aquí las razas condenadas no son negras, sino blancas:

Dios crio a un hombre y a una mujer. Ambos eran negros. Andando el tiempo el matrimonio tuvo dos hijos que se llamaban Caín y Abel. Caín fue el malo y perverso, pues, de chiquito, se dedicó al trago, a las mujeres y al juego. Abel, por el contrario, fue bueno. Oía misa y respetaba a sus padres y las cosas ajenas, y cumplía sus compromisos. Caín, envidioso de su hermano, lo mató una tarde al volver del trabajo. Pero como no hay crimen oculto, Dios se le presentó y, reprochándole su falta, lo maldijo. La canillera (temblor de piernas) de Caín fue tan grande que palideció hasta tomar el color blanco que conservó, hasta su muerte. Caín fue el padre de la nación blanca que hay sobre la tierra. (Velásquez 1960b, 11)

El mito del origen de la raza blanca revela una resignificación del mito originario de la humanidad analizado por Losonzcy (1999) ${ }^{13}$, que complejiza "el motivo de la mala elección" para pensar la "superioridad" de los europeos. Como lo señaló Alfredo Vanín (1996), se trata de un cuento picaresco de la nación blanca que refleja una crítica invencible contra los poderes dominantes. El mito nos recuerda a Adán y Eva; sin embargo, los protagonistas son negros. Caín es el hijo malo y Abel el bueno. Caín es el pecador que dio origen a la nación blanca, que, en su figura, encarna los prejuicios y estereotipos raciales que la Iglesia católica y algunos intelectuales mestizos, como Agustín Codazzi, Laureano Gómez, Miguel Jiménez López y Luis López de Mesa, popularizaron a principios de 1900 en contra de las comunidades negras (Friedemann 1984; Pisano 2012; Wade 1993).

El mito señala una característica propia del pensamiento libertario recreado en el palenquero literario, su memoria parece constituida sobre la base de un doble vacío. Losonzcy (1999) plantea que en la memoria colectiva afrocolombiana no hay registros explícitos de la esclavitud y el origen africano; estos se camuflan y mimetizan en actos cotidianos, rituales y tradiciones culturales. En este sentido, el intelectual palenquero literario despliega actos de camuflaje de la africanía en prácticas católicas como estrategias de reexistencia frente a la violencia e imposiciones del opresor (Losonczy 1999). Por otro lado, la ausencia explícita de una referencia a la esclavitud se expresa en la manera como se alude a aspectos como el color de la piel, su orden jerárquico y las diferencias antagónicas. 
En el relato oral, ser blanco es una maldición impuesta por Dios, no una virtud. Por su crimen, la nación blanca representa la envidia y el pecado original, mientras que Abel encarna todo lo opuesto: es un ser bueno y representa a la nación negra, asesinada por la avaricia de los blancos ${ }^{14}$ - avaricia que nos recuerda el origen del sistema económico capitalista que cobró la vida de millones de seres humanos esclavizados en las Américas-. De esta forma, las bases culturales y simbólicas (mitologías, leyendas, cuentos, música, etc.) de la etnogénesis de la nación cultural afrocolombiana, que menciona Óscar Almario (2001), también se encuentran en las experiencias que dieron lugar a una contramemoria libertaria que se ubica por fuera de la versión bíblica de la Iglesia católica. En otras palabras, lo que nos revela el relato anterior sobre el origen de las naciones es una lectura oral alternativa al dogma del saber "escolástico [que] preconizaba el origen común de todos los seres humanos en la generación de [un] Adán [blanco]" (Chávez 2007). La cantata y el relato del origen de la nación negra, así como otros que se encuentran en los trabajos de Rogerio Velásquez, son muestras de un pensamiento que en vez de alzar sus armas como lo hicieron los cimarrones en la Colonia, alzan sus voces para cantar y contar sus deseos de libertad sin ningún mandarín que los mande.

Partiendo de los mundos relacionales que propone Arturo Escobar (2015), podríamos decir que el pensamiento libertario supone una lucha de tipo ontológico que ha dado las pautas necesarias para la construcción de un mundo afrocolombiano relacional, donde "nada (ni los humanos ni los no-humanos) preexiste [a] las relaciones que lo[s] constituye[n]" (93):

$\mathrm{Al}$ pie de altares familiares, dominados por vírgenes y santos, se desarrollan competiciones poéticas entre los asistentes. Divididos en grupos de cantadoras con representación de un vocero, se despliega una lírica disputa que da lugar a cuartetas raudas y vivaces noticias de la tierra y del río, del árbol, del amor y de la muerte, según lo propusiera su contrario. (Velásquez 1960b, 83)

En mi opinión, el palenque literario debe ser visto como el lugar donde se lleva a cabo una lucha almada (Olarte y Olarte [1988] 2012) por la vida material y espiritual, propia de las guerras de posición de las que habla Gramsci.

Actualmente, un sector del movimiento social afrocolombiano sostiene que las dinámicas territoriales negras comenzaron con el proyecto libertario de

14 El relato "Origen de la raza blanca" también se puede leer como una alternativa oral a la interpretación del pasaje del Antiguo Testamento que relata como Cham, "tercer hijo del patriarca Noé y quien, en una ocasión en que vio borracho a su padre, se burló de su desnudez". Por lo tanto, fue maldecido y sus descendientes condenados a servir por siempre como esclavos de los descendientes de Seth y Jafet (Chávez 2007). 
los cimarrones y "continúan en el presente con la resistencia cultural al mercado y la economía capitalista” (Escobar 2015, 94). Considero que lo anterior ha sido posible, en gran parte, por el papel que han desempeñado la emergencia y la producción autónoma de espacios locales públicos afrocolombianos, propuestos aquí como palenques literarios, que han permitido preservar y recrear las formas ontológicas de la cultura afrocolombiana:

Porque el negro canta para liberarse, herir, amar u odiar. Canta en el recuerdo, en los conflictos sociales, en las supersticiones que dominan los grupos no trasculturados, en los mitos y en las leyendas, al beber y al alimentarse. Podría decirse que el canto es un élan vital que lo pone en función de lo superior y en concordancia con su tradición y su carácter, con su costumbre y con su lengua, con su arte, su religión y su destino que lo hace caer y levantarse. (Velásquez 1948, 22)

Estas construcciones de sentido sobre la tradición oral y el territorio señalan la capacidad intelectual de Velásquez de posicionarse en registros de pensamiento alternativos al predominante en los años sesenta, cuando estudiar negros no era hacer antropología (Friedemann 1984). Intelectuales y figuras públicas blanco-mestizas como Laureano Gómez, Miguel Jiménez López, Agustín Codazzi, entre otros, consideraban el Pacífico como el lugar del atraso donde se encontraban negros perezosos, bárbaros y estúpidos (Friedemann 1984; Pisano 2012; Villegas 2008; Wade 1993). Por otro lado, el Estado colombiano promulgó la Ley 2, que definió las tierras del Pacífico como "baldías” (Villa 2000). Según Escobar (2008), desde comienzos del siglo XX, ha predominado una visión físicogeográfica que ve a esta región como compuesta de ricos y vastos recursos mineros y naturales aptos para la extracción y explotación capitalista.

En contraste, lo examinado en este artículo permite observar un pensamiento que se distancia de construcciones racializadas que negaron la existencia de una cultura afrocolombiana y sus formas de organización social y cultural alrededor de la tradición oral o arte literario. A lo que me refiero con palenque literario es al entendimiento de Velásquez de la tradición oral afrocolombiana como organizadora de relaciones sociales y culturales en el Pacífico colombiano. Considero que esta construcción de sentido se suma a otras sobre el territorio a las que Arturo Escobar ha denominado estrategias subalternas de localización (subaltern strategies of localization) $(2008,59)$. Se trata de modelos o pensamientos alternativos de vida y sociedad que disputan y proponen significados distintos a los promovidos por el capitalismo y la modernidad.

En este sentido, según Alfredo Vanín (2012), pensamientos alternativos sobre el territorio se pueden encontrar en novelistas como 
Arnoldo Palacios [que] crea un territorio urbano surgido de sus personajes, un territorio visceral donde el hambre y la rabia quisieran destruir la ciudad para construir otra sin explotaciones. [...] Payán Archer y Helcías Martán y Faustino Arias elaboraron territorios míticos a partir de lo cotidiano o lo asombroso, partiendo de las leyendas que circulaban en sus pueblos de Tumaco, Guapi, Buenaventura o Barbacoas, al igual que Licona en Quibdó. (6)

\section{Comentarios finales}

En este artículo analicé el pensamiento crítico afrocolombiano de Rogerio Velásquez Murillo y argumenté que su intelectualidad se distanció de la visión hegemónica del territorio de la región pacífica y la población afrocolombiana en la década de los sesenta. Las construcciones de sentido sobre la tradición oral y la territorialidad en su obra muestran un esfuerzo por distanciarse de representaciones andinocéntricas. A mi entender, con el arte y el palenque literario, Rogerio Velásquez asume una defensa de la cultura y el territorio afrocolombiano en contra de las lecturas racistas promovidas por intelectuales blancos mestizos en los centros urbanos (Villegas 2008). Así, el pensamiento crítico afrocolombiano de Rogerio Velásquez se define por su capacidad reflexiva sobre los acontecimientos históricos y las formas de poder que devinieron en la dimensión performativa del mestizaje (Villegas 2008): la invisibilización y la negación de la existencia de una cultura negra en Colombia. En este sentido, Velásquez entró en una batalla ideológica (Wallerstein 1999) o guerra de representaciones (Hall 2000) contra ideas de lo afro como salvaje, bárbaro e incivilizado, así como también del territorio sin población y cultura, apto para la explotación industrial y minera.

La metonimia palenque literario es una provocación de sentido que nos remite a una continuidad histórica de las formas de resistencia de los palenques cimarrones. A diferencia de una fortificación organizada para las guerras de maniobra, el palenque literario se presume como organización social y cultural para la circulación de un pensamiento libertario y relacional como expresión del arte literario. En tal sentido, propongo considerar el palenque literario como escenario social y cultural propio de los espacios públicos afrocolombianos, gracias a los cuales han sido posibles la construcción y circulación de ideas y pensamientos críticos que han cuestionado el proyecto de modernidad y el orden racial colombiano. 
El presente artículo también es una provocación intelectual y académica en tanto sugiere formas alternativas de lucha social que escapan al radar de los teóricos de los movimientos sociales y políticos en las ciencias sociales. El pensamiento crítico y los espacios públicos subalternos que abre son instancias que hacen parte de un largo proceso social y político, el cual cultiva visiones alternativas del mundo que luego dan paso a movilizaciones identitarias y políticas (Fraser 1990). De ahí la importancia de examinar no solo el pensamiento crítico de Rogerio Velásquez, sino también el valor de la tradición oral como formadora de espacios públicos subalternos o contradiscursos afrocolombianos. Pienso que Velásquez nos dejó un legado que debemos mirar con detenimiento, sobre todo, su idea de palenque literario que tiene, sin duda, un potencial analítico y político para entender la larga historia de lucha social y cultural afrocolombiana y sus repertorios de acción cultural.

Rogerio Velásquez no fue el único intelectual afrocolombiano que a mitad del siglo XX desarrolló un pensamiento crítico que cuestionó el proyecto de modernidad y el orden racial colombiano, como lo demuestra la literatura al respecto (Arboleda 2010, 2016; Caicedo 2013; Friedemann 1984; Leal 2007; Mina 2006; Ortiz 2007; Pisano 2012; Prescott 1997; Valderrama 2013, 2016; Vanín 2012; Zapata-Cortés 2010). A mediados del siglo XX hubo una convergencia de figuras representativas de las comunidades negras, como Teófilo Potes, Rogerio Velásquez, Delia y Manuel Zapata, Arnoldo Palacios, Teresa Martínez, Jorge Artel, Helcías Martán Góngora, Hugo Salazar Valdés y Otto Morales Benítez; literatos y políticos como Natanael Díaz, Diego Luis Córdoba; músicos y folcloristas como Esteban Cabezas, Leonor González Mina, Margarita Hurtado, Casaman, Alicia Camacho, Mercedes Montaño, Madolia de Diego y Totó la Momposina; humanistas y académicos como Aquiles Escalante, entre otros. Estos intelectuales y artistas fueron claves en la construcción de un campo político intelectual afrocolombiano (Arboleda 2016) que se constituyó en una red de relaciones y colaboraciones (Valderrama 2014). Mi propuesta es seguir indagando acerca de sus producciones artísticas, escritas y musicales, para contribuir con lo que podríamos denominar una formación colectiva de pensamiento afrocolombiano - atravesado por la heterogeneidad y la diferencia - frente a las cuestiones raciales del país. 


\section{Referencias}

\section{Fuentes primarias}

Velásquez, Rogerio. 1948. "Notas sobre el folklore chocoano". Revista de la Universidad del Cauca 12: 21-29.

—. 1959a. “Cuentos de la raza negra”. Revista Colombiana de Folclor 3: 1-21.

—. 1959b. "La canoa chocoana en el folklore”. Revista Colombiana de Folclor 3: 109-126.

—.1960a. "Leyendas y cuentos de la raza negra”. Revista Colombiana de Folclor 4: 71-120.

—. 1960b. “Cantares de los tres ríos”. Revista Colombiana de Folclor 2 (5): 13-99.

—.1960c. “Adivinanzas del Alto y Bajo Chocó”. Revista de Folklore 5: 103-129.

—. 1962. "Gentilicios africanos en el occidente de Colombia”. Revista Colombiana de Folclor 3 (7): 109-148.

\section{Fuentes secundarias}

Agudelo, Carlos Efrén. 2005. Multiculturalismo en Colombia: política, inclusión y exclusión de poblaciones negras. Medellín: La Carreta; ICANH; Universidad Nacional.

Almario, Óscar. 2001. "Tras las huellas de los renacientes. Por el laberinto de la etnicidad e identidad de los grupos negros o afrocolombianos del Pacífico sur.” En Acción colectiva, Estado y etnicidad en Colombia, editado por Mauricio Pardo, 15-41. Bogotá: ICANH; Colciencias.

Antón Sánchez, John. 2003. "Rogerio Velásquez y su aporte a la teoría social de la diversidad en Colombia”. En 150 años de la abolición de la esclavización en Colombia. Desde la marginalidad a la construcción de la nación, editado por Museo Nacional de Colombia, 754-775. Bogotá: Ministerio de Cultura; Cerlalc; Fundación Beatriz Osorio Sierra; Aguilar; Convenio Andrés Bello; Museo Nacional de Colombia.

Arboleda, Santiago. 2010. "El mestizaje radical de Manuel Zapata Olivella: raza, etnia y ciudadanía”. En Mosquera, Lao-Montes y Rodríguez 2010, 441-486.

-. 2016. Le han florecido nuevas estrellas al cielo: suficiencias íntimas y clandestinización del pensamiento afrocolombiano. Cali: Poemia.

Arocha, Jaime y Lina del Mar Moreno. 2007. "Andinocentrismo, salvajismo y afro-reparaciones”. En Afro-reparaciones: memorias de la esclavitud y justicia reparativa para negros, afrocolombianos y raizales, editado por Claudia Mosquera y Luiz Claudio Barcelos, 73-94. Bogotá: Universidad Nacional de Colombia.

Caicedo, José. 2013. A mano alzada. Memoria escrita de la diáspora intelectual afrocolombiana. Popayán: Sentipensar. 
Castro-Gómez, Santiago. 2007. “Disciplinar o poblar? La intelectualidad colombiana frente a la biopolítica (1904-1934)”. Revista Nómadas 26: 44-55.

Chávez, María Eugenia. 2007. “Color, inferioridad y esclavización: la invención de la diferencia en los discursos de la colonialidad temprana”. En Afro-reparaciones: Memorias de la esclavitud y justicia reparativa para negros, afrocolombianos y raizales, editado por Claudia Mosquera y Luiz Claudio Barcelos, 73-94. Bogotá: Universidad Nacional de Colombia.

Dawson, Michael. 2001. Black Visions. The Roots of Contemporary African-American Political Ideologies. Chicago: University of Chicago Press.

Escobar, Arturo. 2008. Territories of Difference: Place, Movements, Life, Redes. Durham NC: Duke University Press.

-. 2015. "Territorios de diferencia: la ontología política de los ‘derechos al territorio”'. Revista Desenvolvimiento e Meio Ambiente 35: 89-100. DOI: 10.5380/dma.v35i0.43541.

Essed, Philomena y David Theo Goldberg, eds. 2002. Race Critical Theories: Text and Context. Massachusetts: Blackwell.

Fanon, Frantz. (1963) 2004. The Wretched of the Earth. Nueva York: Grove Press.

Farred, Grant. 2003. What's my Name: Black Vernacular Intellectuals. Minneapolis: University of Minnesota Press.

Flórez Flórez, Juliana. 2010. Lecturas emergentes. Decolonialidady subjetividad en las teorías de movimientos sociales. Bogotá: Pontificia Universidad Javeriana.

Fraser, Nancy. 1990. "Rethinking the Public Sphere: A Contribution to the Critique of Existing Democracy”. Social Text 25/26: 56-80.

Friedemann, Nina S. de. 1984. "Estudios de negros en la antropología colombiana: presencia e invisibilidad”. En Un siglo de investigación social, editado por Nina S. de Friedemann y Jaime Arocha, 507-572. Bogotá: Etno.

Gramsci, Antonio. 1971. Selections from the Prison Notebooks. Nueva York: International Publishers.

-. 2006. "State and Civil Society." En The Anthropology of the State: A Reader, editado por Aradhana Sharma y Akhil Gupta, 71-86. Malden, Oxford, Carlton: Blackwell.

Gregory, Steven. 1998. Black Corona Race and the Politics of Place in an Urban Community. Princeton, NJ: Princeton University Press.

Habermas, Jürgen. 1991. The Structural Transformation of the Public Sphere. An Inquiry into a Category of Bourgeois Society. Cambridge MA: MIT Press.

Hall, Stuart. 1997. “The Work of Representation.” En Representation: Cultural Representation and Signifying Practice, editado por Stuart Hall, 13-74. Londres: Open University, Sage Publication.

-.2000. “Conclusion: The Multicultural Question”. En Un/settled Multiculturalisms: Diasporas, Entanglements, Transruptions, editado por Barnord Hesse, 209-241. Londres: Zed Books.

Hanchard, Michael. 2006. Party/Politics: Horizons in Black Political Thought. Nueva York: Oxford University Press. 
Lao-Montes, Agustín. 2010. "Cartografías del campo político afrodescendiente en América Latina”. En Mosquera, Lao-Montes y Rodríguez 2010, 281-328.

Lawrence, N. William. 2007. The Basics of Social Research: Qualitative and Quantitative Approaches. Boston, MA: Pearson.

Leal, Claudia. 2007. "Recordando a Saturio. Memorias del racismo en el Chocó (Colombia)". Revista de Estudios Sociales 27: 79-93.

-. 2010. "Usos del concepto de raza en Colombia”. En Mosquera, Lao-Montes y Rodríguez 2010, 389-438.

Losonczy, Anne-Marie. 1999. "Memorias e identidad: los negros-colombianos del Chocó”. En De montes, ríos y ciudades: territorios e identidades de la gente negra en Colombia, editado por Juana Camacho y Eduardo Restrepo, 13-24. Bogotá: Ecofondos; Fundación Natura; ICANH.

Melucci, Alberto. 1999. Acción colectiva, vida cotidiana y democracia. Ciudad de México: El Colegio de México.

Mina Aragón, William. 2006. Manuel Zapata Olivella: pensador humanista. Cali: Artes Gráficas del Valle.

Mosquera Rosero-Labbé, Claudia, Agustín Lao-Montes y César Rodríguez Garavito. 2010. Debates sobre ciudadanía y políticas raciales en las Américas negras. Bogotá: Universidad Nacional de Colombia.

Motta González, Nancy. 1997. Hablas de selva y agua: la oralidad afro-pacífica desde una perspectiva de género. Cali: Universidad del Valle; Centro de Género, Mujer y Sociedad; Instituto de Estudios del Pacífico.

Olarte Reyes, Estefan y Óscar Olarte Reyes. (1988) 2012. Presentación a Prisioneros del ritmo del mar, libertarios de la tierra firme, editado por Estefan Olarte Reyes, 7-8. Cali: Feriva.

Omi, Michael y Howard Winant. 1994. Racial Formation in the United States. From the 1960s to the 1990s. Nueva York: Routledge.

Ortiz, Lucía, ed. 2007. Introducción a Chambacú, la historia la escribes tú. Ensayos sobre cultura afrocolombiana, editado por Lucía Ortiz, 13-46. Madrid: Iberoamericana.

Oslender, Ulrich. 1999. “Espacio e identidad en el Pacífico colombiano”. En De montes, ríos y ciudades: territorios e identidades de la gente negra en Colombia, editado por Juana Camacho y Eduardo Restrepo, 25-48. Bogotá: Ecofondos; Fundación Natura; ICANH.

-. 2003. “'Discursos ocultos de resistencia’: tradición oral y cultural política en comunidades negras de la costa pacífica colombiana”. Revista Colombiana de Antropología 39: 203-235.

-. 2011. Comunidades negras y espacio en el Pacífico colombiano. Hacia un giro geográfico en el estudio de los movimientos sociales. Bogotá: ICANH.

Patiño, Germán. 2010. Prólogo a Ensayos escogidos/Rogerio Velásquez, compilado por Germán Patiño, 9-40. Bogotá: Ministerio de Cultura.

Pedrosa, Álvaro, Alfredo Vanín y Nancy Motta. 1994. La vertiente afropacífica de la tradición oral. Cali: Universidad del Valle. 
Pisano, Pietro. 2012. Liderazgo político negro en Colombia 1947-1964. Bogotá: Universidad Nacional de Colombia.

Prescott, Laurence. 1996. "Perfil histórico del autor afrocolombiano: problemas y perspectivas”. América Negra (Pontificia Universidad Javeriana, Bogotá) 12, 104-129. http://www. javeriana.edu.co/documents/5782625/5900951/AmericaNegra12.pdf/b2fcbfcf-764c-40e6999c-a9fac9313c4c.

- 1999. "Evaluando el pasado, forjando el futuro: estado y necesidad de la literatura afrocolombiana”. Revista Iberoamericana LXV (188-189): 553-565. doi:https://doi.org/10.5195/ reviberoamer.1999.6043.

Rivas Lara, César E. 2008. Tres grandes afrocolombianos: Rogerio Velásquez, Arnoldo Palacios, Miguel A. Caicedo. Medellín: Lealon.

Solarte B., Ana B. 2008. "La palabra: tradición oral y literatura afrocolombiana”. En Cátedra de Estudios Afrocolombianos. Aportes para maestros, coordinado por Axel Rojas, 243-256. Popayán: Universidad del Cauca.

Trouillot, Michel-Rolph. 2003. “Adieu, Culture: A New Duty Arises”. En Global Transformations. Anthropology and the Modern World, 97-117. Nueva York: Palgrave Macmillan.

Valderrama, Carlos. 2013. "Folclore, raza y racismo en la política cultural e intelectual de Delia Zapata Olivella. El campo político-intelectual afrocolombiano”. Revista CS 12: 259-296.

-. 2014. "Black Politics of Folklore. Expanding the Sites and Forms of Politics in Colombia". Tesis de Maestría en Sociología. University of Massachusetts, Amherst.

-. 2016. "Intelectualidad crítica afrocolombiana: la negredumbre en el pensamiento intelectual de Rogerio Velásquez Murillo”. Nómadas 45: 215-227.

Vanín, Alfredo. 1996. "Lenguaje y modernidad”. En Pacífico: ¿Desarrollo o diversidad? Estado, capital y movimientos sociales en el Pacífico colombiano, editado por Arturo Escobar y Álvaro Pedrosa, 41-65. Bogotá: Cerec.

-. 2012. "Territorios cantaos en la poética popular del Pacífico”. Ponencia presentada en la Universidad del Valle, sede Buenaventura.

Vété-Congolo, Hanétha. 2016. “Caribbean Interorality: A Brief Introduction”. En The Caribbean Oral Tradition. Literature, Performance, and Practice, editado por Hanétha VétéCongolo, 1-55. Nueva York: Palgrave Macmillan.

Villa, William. 1998. "Movimiento social de comunidades negras en el Pacífico colombiano: la construcción de una noción de territorio y región”. En Geografía humana de Colombia: los afrocolombianos, vol. 6, editado por Adriana Maya, 345-359. Bogotá: Instituto Colombiano de Cultura Hispánica.

Villegas Vélez, Álvaro. 2008. "Nación y alteridad en Colombia: la población negra y la colonialidad del poder”. Revista Colombiana de Antropología 44 (1): 71-94.

Wade, Peter. 1993. Blackness and Race Mixture: The Dynamics of Racial Identity in Colombia. Baltimore: Johns Hopkins University Press. 
Wallerstein, Immanuel. 1999. "La cultura como campo de batalla ideológico del sistema mundo moderno”. En Pensar (en) los intersticios. Teorías y prácticas de la crítica poscolonial, editado por Santiago Castro-Gómez, Óscar Guardiola-Rivera y Carmen Millán de Benavides, 163-189. Bogotá: Pontificia Universidad Javeriana.

Zapata Olivella, Manuel. 1983. "La tradición oral, una historia que no envejece”. En El negro en la historia de Colombia: fuentes escritas y orales. Primer Simposio sobre Bibliografía del Negro en Colombia, octubre 12-15. Bogotá: Fondo Interamericano de Publicaciones de la Cultura Negra de las Américas; Unesco. 